\section{Por um paradigma da(s) mobilidade(s)}

\author{
Eduardo Marandola Jr.*
}

URRY, John. Mobilities. London: Polity, 2007. 335p.

De tema de pesquisadores dedicados ao estudo dos transportes, a mobilidade tornou-se uma questão importante nas ciências sociais deste século, aparecendo nas publicações e pesquisas dedicadas ao tema recentemente. O novo livro de John Urry, um dos principais sociólogos dedicados ao estudo da mobilidade contemporânea, é uma das mais significativas contribuições nos últimos anos, principalmente devido ao fundo teórico que reclama para o tratamento da questão. Mobilities, lançado em 2007, é uma proposta ousada de construção de um novo paradigma das mobilidades, à maneira de Kuhn, como um paradigma que orienta uma "ciência normal". Segundo Urry, a mobilidade é um complexo fenômeno social que ultrapassa as dimensões físicas, corporais e econômicas, envolvendo também as dimensões cultural, afetiva, imaginária, espacial e individual.

A dimensão paradigmática das mobilidades contemporâneas (sempre referidas pelo autor no plural, devido a suas múltiplas naturezas, origens, periodicidades e sentidos) está na sua condição estruturante da própria sociedade. Urry, um estudioso da teoria da complexidade e da sociologia do conhecimento, aponta os modernos meios de transporte e comunicação como estruturantes e reveladores dos mecanismos de reprodução social. Móveis e não-móveis são elementos centrais que estabelecem relações entre pessoas, mercadorias, informações e ideias. Segundo Urry, a teoria social necessita encarar este paradigma das mobilidades como pós-disciplinar, o qual exige métodos, teorias, questões e soluções diferentes, diante de uma paisagem metodológica e social eivada por estas formas e estruturas sociais.

Tempo, redes, transporte, comunicação e informação não são meros elementos presentes na vida contemporânea. Segundo Urry, eles são a própria forma como esta vida em sociedade se organiza e se reproduz, reclamando, por isso, uma postura mais ousada por parte dos cientistas sociais quando vão pensar as mobilidades e suas interpenetrações na vida e nas instituições sociais.

O livro é dividido em três partes, entre as quais se organizam os 13 capítulos da obra:

Parte 1 - Mobile worlds

1. Mobilizing social life

2. 'Mobile' theories and methods

3. The mobilities paradigm

Parte 2 - Moving and communicating

1. Pavements and paths

2. 'Public' trains

3. Inhabiting cars and roads

4. Flying around

5. Connecting and imagining

6. Gates to heaven and hell

Parte 3 - Societies and systems on the move

1. Networks

2. Meetings

3. Places

4. Systems and dark futures

A primeira parte é dedicada à elaboração do paradigma das mobilidades, em que o autor defende a natureza social contemporânea como estando em movimento. Ele parte de um conjunto de 12 tipos de

\footnotetext{
* Geógrafo, Núcleo de Estudos de População, Universidade Estadual de Campinas (Nepo/Unicamp).
} 
mobilidades que, em sua opinião, expressam as possibilidades de movimento e suas implicações sociais, entre as quais a migração de refugiados e sem teto; viagens profissionais e de negócios; excursões de estudantes ou de jovens; viagens para spas, hospitais ou outros tratamentos médicos; mobilidade de forças militares; viagens de aposentados; viagens de turismo; visitas a amigos e parentes ou a membros de redes sociais identitárias; viagens relacionadas a trabalho, incluindo pendularidade; entre outras. A análise destas várias formas de mobilidade revela, na opinião do autor, diferentes formas de relacionamento com o lugar e suas distintas características, o que permite pensar a dimensão da mobilidade enquanto componente da própria vida social.

Cada movimento é sempre acompanhado de riscos e, no cenário atual de mudanças ambientais globais, Urry chama atenção para a importância crescente que restrições ambientais irão impor às mobilidades. Em vista disso, é fundamental incluir nesta reflexão os processos de expulsão e restrição não apenas de fluxos migratórios, mas também de entrada, trânsito e saída de pessoas.

Na segunda parte do livro, Urry procura alicerçar seu argumento por meio da análise de tipos específicos de transporte e comunicação, ponderando sua acessibilidade. Isso permite pensar a dimensão dos móveis e imóveis a partir das estruturas e sua fluidez. A ideia de sistema é a chave do raciocínio, por meio da qual o autor aponta as mobilidades diferenciais e a importância do capital social e dos espaços de encontro na qualificação das mobilidades e de sua significância sociocultural.

O autor contrapõe a racionalidade da estruturação dos sistemas de comunicação e transporte à lógica dos deslocamentos cotidianos e sociais, mostrando a discrepância e a ênfase que os primeiros dão à produção e ao consumo, enquanto os segundos se organizam a partir de relações pessoais, familiares e de símbolos culturais. Enquanto a estrutura se fia por uma lógica racionalizada, as mobilidades são fruto de interações orgânicas que se adaptam e atribuem significados distintos às cifras, trilhos, tempos e estações.

Na terceira parte, Urry afunila seu argumento para os lugares (situações) nodais das mobilidades, tais como os portões, redes, encontros e lugares. $\mathrm{O}$ autor procura construir toda uma sociologia das mobilidades composta por encontros e lugares em movimento, que exigem novas formas de estabelecimento de vínculos sociais e de organização política. Se esta sociedade em movimento trouxe uma fluidez às relações sociais e aos espaços, isto não implica necessariamente uma perda de sua intensidade ou valor. A sociedade e os sistemas estão em movimento, juntamente com as pessoas, e cada vez mais papéis e funções são desempenhados fora da fixidez, em movimento.

A natureza, por fim, deste novo paradigma social que Urry defende está em descristalizar a fixidez, encarando o movimento como inerente à forma de organização social do século $\mathrm{XXI}$, à medida que tudo pode se feito, até simultaneamente, estando móvel ou imóvel.

Seu argumento não conduz necessariamente a uma apologia do movimento, ou a uma contraposição categórica entre duas categorias de grupos sociais: os móveis e os não-móveis. O que a obra e seu itinerário intelectual propõem é uma ampliação dos horizontes para pensarmos a dinâmica populacional na sociedade contemporânea, que se notabilizou historicamente por uma análise em que espaço e tempo pouco convergiram. Pensar em uma sociedade em movimento é aceitar a busca de um paradigma que permita entender a multidimensionalidade das mobilidades e seu caráter intrínseco ao viver contemporâneo. 